\title{
Tresa Pollock Looks to the Future of Metallurgical and Materials Transactions \\ Lynne Robinson
}
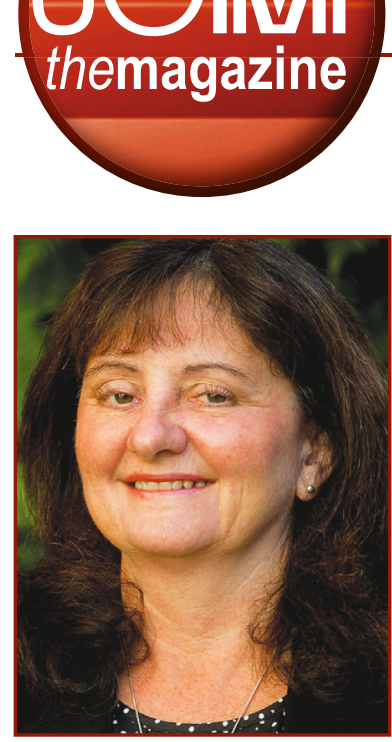

Tresa Pollock
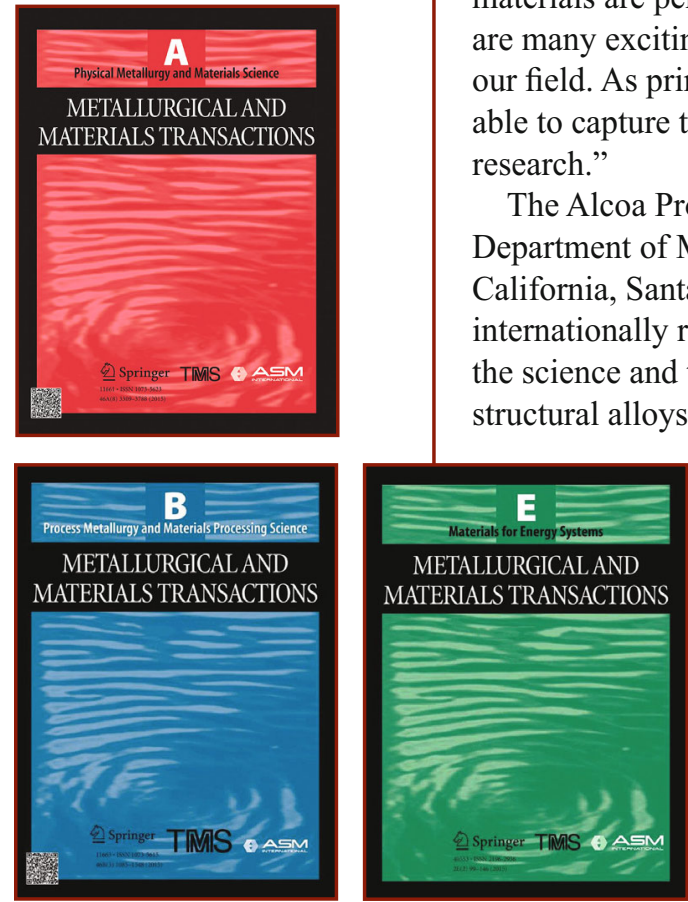

Jointly published by TMS and ASM International, Metallurgical and Materials Transactions encompasses three highly respected, peerreviewed archival journals for metallurgy and materials science. To access these and other TMS journals, visit the TMS Knowledge Resource Center at knowledge.tms.org. By logging in to SpringerLink via the TMS website, TMS members can read the current issues and archives of all of these journals for free.

\section{TMS content update}

Look for news and updates on TMS publications and online resources, as well as opportunities for editors and authors, in this regular JOM feature.

Positioning Metallurgical and Materials Transactions (Met Trans) for even greater success and impact in a rapidly changing scientific and publishing environment is a priority for Tresa M. Pollock as the new principal editor of the Met Trans family of publications.

"Met Trans has a distinguished history of publishing high quality, high impact research with a strong emphasis on metallic materials. There is no other journal that covers topics on metallic materials to the same depth," Pollock said. "While metallic materials are perceived to be mature, there are many exciting things happening now in our field. As principal editor, I hope to be able to capture the best and most exciting search."

coa Professor and chair, inent of Materials, University of Cornia, Santa Barbara, Pollock brings ationally recognized expertise in the science and technology of advanced structural alloys to her editorship. She notes that her involvement with Met Trans has factored prominently in her career, starting with publication in Met Trans $A$ of her undergraduate senior thesis project on flow localization during plane strain stretching of a ferritic-austenitic steel. She has since published more than 40 papers in Met Trans, contributed as a reviewer, and has served as an associate editor of Met Trans A since 1997.

Pollock's current interests encompass the mechanical and environmental performance of materials in extreme environments, unique high temperature materials processing paths, ultrafast laser-material interactions, alloy design, and 3-D materials characterization. The 2005 TMS President and a 2009 TMS Fellow, Pollock is regarded as a thought leader on issues of critical importance to the field and has provided leadership to an array of national initiatives on these topics.

Assuming the Met Trans editorship on September 1, 2016, Pollock will work with current principal editor, David Laughlin, through the end of 2016 when he steps down from the position. Pollock said that the Met Trans editorial team plans to engage in strategic planning to examine content and process refinements. "There will be efforts to attract some new topical areas that are a natural fit with the journal," she said. "We will also be working to further increase the impact of Met Trans, as well as speed up the paper review process. The world moves very fast and we would like to get publications to the community faster."

Pollock also indicated that her perspective on the widespread impact of materials advances on industry and society will inform the directions that she explores as Met Trans principal editor. "I am looking forward to thinking about how the Met Trans family of journals can serve our current and future technical communities as well as greater societal needs, reflected in, for example, the National Academy of Engineering's Grand Challenges (www .engineeringchallenges.org),"she said. "This evolution will need to occur within the backdrop of rapidly changing business models for academic/scholarly publication, where there are strong driving forces for open access and open data, combined with explosive growth of research and publications from across the globe." 